\title{
Joint-use libraries
}

Edited by William Miller, Rita M Pellen.

New York: Haworth Information, 200I. 150p.

ISBN $078902070 \times$ (hb); ISBN 07890 207I 8 (sb)

Price: US\$39.95 (hb); US\$24.95 (sb)

\section{Cooperative efforts of libraries.}

Edited by William Miller, Rita M Pellen.

New York: Haworth Information, 2002. 273p.

ISBN 0789021870 (hb); ISBN 0789021889 (sb)

Price: US\$59.95 (hb); US\$34.95 (sb)

"You librarians are light years ahead of us" - so an American academic is quoted in the introduction to these books, when confronted with his university library's cooperative ventures. The refrain "librarians are good at cooperating" runs through these two "separates", special monographs published simultaneously as the journal Resource Sharing \& Information Networks, Volume 15, Number I, 200 I and Volume 16, Numbers I and 2, 2002, respectively. Surely the comment can be applied to South Africa - where our libraries' consortia might well show the way in the current higher education mergers and where our public library systems rely on cooperation between provincial and local governments (however uncertain that particular partnering might be at the moment). However, a closer look at the case studies inside these two books reveals how limited our vision has been. Despite all the calls for "transformed" library structures in the early 1990s, we still have separate library sectors - public, academic, school, special - , with little cooperation among them beyond interlibrary lending.

SA JnI Libs \& Info Sci 2004, 70(2) 
The almost exclusively American focus of these two books might repel some readers; the terminology and the legal references demand patience at times. But the lasting impression is of a pioneering vigour and dynamism. In response to tighter budgets and demands for better library services from diverse communities, American librarians have broken down traditional barriers to find innovative models. The case studies in these two books inspire with their fresh vision.

Joint-use libraries deals with the "ultimate" form of cooperation - the growing trend towards amalgamation of two or more libraries to serve the needs of two or more different client groups. In South Africa, the term "joint-use" tends to be used in relation to school and public library combinations; yet only one of the nine chapters of this book refers to school libraries. The others describe mergers of tertiary-level academic libraries and public libraries: of university and community college libraries; and of university and community college and public libraries. Different models have emerged. Some libraries just share a building; some merge technical departments but run some separate public services, such as children's rooms and student reserve collections; some merge everything, aiming at a seamless library service. Successful amalgamations begin with the recognition that each prospective partner has something to offer. The university, for example, might have funds for a new library building, and the city might have land at a good site. The context often is pressure from the public and the campus for better services, together with inadequate funds to build a large new library. A strong theme in all the case studies is the importance of community engagement. Several of the new libraries were funded by state government bonds and votes after years of community lobbying.

The book tackles those instinctive negative reactions of librarians who are often dubious about the real benefits of joint-use. They see it as a compromise to please politicians and government officials, who look for ways of saving money. The case studies are written by practitioners intimately involved in the merging processes. They agree that the amalgamation has resulted in levels of service that are better than those they could have achieved singly. Public library members have access to deeper collections and to better Information and Communication Technology (ICT). Academic library users have access to the wide public library networks. Both user groups benefit from better information literacy programmes and reference services. The proviso running through all the cases is that these benefits depend on staff attitudes. Successful transformation requires staff members who are excited by the new opportunities of joint use.

Cooperative efforts of libraries has both a broader focus and a narrower one than its companion volume. It gives a number of case studies of less extreme forms of cooperation than joint-use, which have resulted from a combination of two factors - new opportunities provided by ICT and restrictive economic climates. It looks outside the United States in two of its chapters - in one, describing initiatives to improve American library connections to the Caribbean and Latin America; in another, reporting on a pilot document delivery project for the American University of Armenia. The more intense focus comes from its zooming in on specific cooperative activities, such as preservation of print, collection development, storage, and digital reference services.

The book has two parts: the first describes nine cases of cooperative ventures over geographic areas, and the second gives a sample of eight diverse cooperative activities. Of course, the lines between the two are not that clearly defined. The first chapter thus describes a cooperative project involving a consortium of 270 different libraries of various kinds in the geographic area of New York, which aims at setting up a shared virtual reference desk. The reference desk service will pool the expertise and knowledge of a wide range of library staff. Several of the other case studies involve shared reference services. A thread in the motivation for these new services is the need to provide different kinds of access to students and to stop the recent declines in use statistics. For example only $49 \%$ of the use of Wesleyan University Library in Connecticut, USA, is in-house. Students access the Internet and library databases across the campus and in their residences - at all hours. To provide for their needs, the Reference Now-LiveHelp! supplies a 24-hour, real-time service to the university and a group of small liberal arts colleges. None of the cooperating institutions could do this individually.

Both these books are attractively packaged. They aim at practitioners "on the ground", as well as at students. The authors concentrate on practicalities - spelling out "what we did", "why we did it" and "how we did it". Texts of contracts and agreements supplement the chapters. Several include interviews with key role-players, thus covering the subjective aspects often neglected in more academic texts and found to be crucial in successful cooperation. The books' format - compilations of journal articles, with a useful introduction and adequate index - makes for some repetition. Many of the case studies clearly tackle the same issues and draw on the same body of expertise. However, each does offer a new angle and a different context. What is common to all is a vigorous commitment to providing better services and a willingness to step out from safe barriers.

Reviewed by: Genevieve Hart, Department of Library \& Information Science, University of the Western Cape, South Africa.

Email: ghart@uwc.ac.za 